\title{
Research on the Construction of Open Laboratory and the Cultivation of Applied Talents
}

\author{
Yi-Lin Bei \\ School of information science and technology, Taishan \\ University, Tai'an, China \\ beiyilinok@163.com
}

\author{
De-Yun Yang \\ School of information science and technology, Taishan \\ University, Tai'an 271021, China
}

\begin{abstract}
The opening of professional laboratory in colleges and universities is the foundation and guarantee of cultivating applied talents. In view of the problems existing in the construction of specialized laboratories in colleges and universities, this paper discusses the ways and methods of the open reform of professional laboratories from the aspects of construction idea, open mode, management means and so on. Combining with the actual situation of the university, this paper introduces the provincial demonstration experiment center of Taishan university in this area of exploration, practice and achievements.
\end{abstract}

Keywords-Professional laboratory, open, management, application of talent.

\section{INTRODUCTION}

As a discipline development support, professional laboratory is the focus of all colleges and universities investment and construction. The professional laboratory of colleges and universities is an important base of experimental teaching and scientific research. The teaching content is closer to the professional field and closely follow the development of the subject. The research questions are mostly frontier and hot issues. The methods and methods used are often directly into scientific research, so professional laboratory for the cultivation of students practical ability, scientific literacy, professional knowledge has a more important significance, but also the source to combined with scientific research, production, economy ${ }^{[1,2]}$.

Application of talent is the basic guarantee to complete industrial upgrading and national rejuvenation, at present, colleges and universities to cultivate talent and market and business needs of users out of touch, but also an urgent problem to be solved Therefore, how to cultivate the real needs of the people, is the key to the success or failure of higher education. College students to enhance the application of competence, we must pay attention to experimental teaching, professional laboratory effective use and open is particularly important.

\section{GOALS AND STATUS OF PROFESSIONAL LABORATORY OPEN}

\section{A. Goals}

The professional laboratories discussed in this paper are different from the basic laboratories that undertake general teaching tasks, and their construction and development emphasize innovation and research, focusing on the exploration of professional frontiers. Basically, there are two tasks :

(1) Provide teachers the necessary test equipment, hardware and create a solid material foundation and academic atmosphere, gave birth to more and better research, combined research, the transformation has made landing performance.

(2) According to the size of the laboratory, part or all of the students open, exercise the practical ability of students, participate in the actual project development team, and ultimately complete the basic task of cultivating applied talents in colleges and universities.

\section{B. Status}

In order to understand the students' openness to the professional laboratory, we carried out the questionnaire survey. The questionnaire mainly designed 13 indicators from the aspects of the overall effect, the cultivation of the knowledge of the project, the application innovation of the project, the teaching and the equipment of the teachers and so on. Some other auxiliary indicators, using the Likert 5 scale for questionnaires. The survey participants were mainly 80 students who participated in the open experiment, and collected 76 copies and 70 valid questionnaires.

The results of the survey show that, on the whole, the vast majority of students are open to the open experiment is recognized, to participate in open experiments are interested. But a considerable number of students said that the opening hours and open content is still insufficient, more hope to participate in practical experimental project learning. Survey shows that many students accredited laboratories open approach, but puzzled by aspects of form and foster innovation, the main reason is more dependent on these experiments teacher organizations, students lack initiative. 
In general, modern science and technology with each passing day, in the case of computer science, for example, both theoretical development and technological innovation, research results are emerging, but these results are difficult to be reflected in the experimental teaching, some experimental content, experimental means and even a long time have not changed, experimental teaching has been lagging behind In the development of disciplines ${ }^{[3-5]}$.

On the other hand, limited to the students' ability and cognitive level, often on the layout of the teachers of innovative projects there is fear of fear, poor self-help, but also to some extent restricted the effect of professional laboratory opening.

\section{OPEN LABORATORY RESEARCH}

\section{A. Construction concept}

The concept of laboratory construction is the overall positioning of laboratory functions and functions, is the guiding ideology of laboratory construction and operation。Construction of professional laboratory of colleges and universities have to rely on professionals, taking advantage of the training of professionals, encourage scientific research, social service's needs, thus contributing to the prosperity of disciplines. For a long time, domestic universities generally attach importance to theoretical teaching, but ignore experimental teaching, which results in lack of investment in experimental teaching, lack of innovative mechanism and rigid management. In recent years, domestic colleges and universities gradually realized this problem, began to explore the reform and try, has accumulated a lot of valuable experience, in which professional laboratory is a proven practice of effective and reasonable laboratory management mechanism ${ }^{[6]}$.

\section{B. Open mode}

There are many modes of opening laboratory. According to the degree of opening, laboratory opening is divided into omnibearing opening, appointment opening, regular opening and phased opening. According to the opening content, the laboratory opening is divided into basic experiment, project opening, comprehensive design experiment, project opening, optional experiment, project opening and opening of scientific research project. According to the open object, the laboratory can be divided into open for the designated professional, open to the whole school, open to the industry and open to the community.

Due to the different focus and scale of professional laboratories, open mode can be handled flexibly. For example, some wellequipped professional laboratories can be arranged for some professional courses, training cases regularly open, and set up basic experimental projects and integrated design experimental projects.

Some specialized laboratories serve scientific research, and the main users are key teachers. The purpose is to engage in scientific research or transform scientific research achievements to serve the local economy. This kind of laboratory equipment is advanced, expensive, relatively small in size, can be arranged from time to time or scheduled to open, from the content to arrange scientific research projects, practical exercises, open objects for the designated professional outstanding students.

\section{Management method}

1) Laboratory daily management means

a) Both managers and instructors need a better sense of responsibility and ability to expand their knowledge ;

b) The rate of good laboratory equipment must be maintained, otherwise there is no way to speak of it。Opening up will inevitably lead to an increase in utilization of instruments and equipment. The workload of maintenance and repair will increase. If there is no maintenance technician who has higher maintenance skills, it is difficult to guarantee the planned class hours and the need for opening up ;

c) We should monitor and manage the order and safety of the open laboratory, ensure the normal order and safety environment of the laboratory, and audit and record the process of the experiment.

In order to ensure that the three, not only to train excellent teachers, but also must speed up the informatization construction of laboratory management means, and development or purchase of laboratory management software, to achieve a more accurate and convenient and effective management.

\section{2) Open management measures for students}

The professional laboratory of the University as an important base for teaching and scientific research, undertake multiple functions of experimental teaching, personnel training, scientific training, scientific research and social services, to explore more advanced and scientific means of information management at the same time, we should pay attention to students' participation in learning motivation and participate in the project in the laboratory. Professional laboratory is to serve more students, but how to fully mobilize the enthusiasm, participation and subjective initiative of the students in the implementation process is also an important topic of laboratory management. 
In order to cultivate a real society, we need talents, and we need to set up actual combat experimental projects according to the frontier and market demand of the discipline development. In order to achieve good experimental results, we try to use three methods:

a) Calculate credits and arrange professional expansion courses in the form of elective courses. This way can effectively improve the enthusiasm of students, but also contribute to the effect and level of open experiments.

b) Organize students to participate deeply in teacher's project and form R \& D team. This approach has proved to be a catalyst for the development of good students.

c) Organize students to participate in various professional skills competitions. As the competition is not the basic class experiment can do, it must be through professional laboratory open way to achieve the purpose of improving technology. This way can bring honor and even material reward to students, it is an effective incentive measure, not only can achieve the goal of training the student, but also can bring more social influence for the school. After several years of trial and promotion, it also has excellent result.

\section{IMPLEMENTATION PLAN}

The provincial computer experimental demonstration center of Taishan University has made a useful exploration on the opening of specialized laboratories according to its own orientation and students' characteristics, and has formed some useful experiences and achieved certain results.

\section{A. Opening measures in experiment time}

Opening in time. In order to provide students in the time of the flexible and abundant, our laboratory task implementation details of the analysis, to negotiate the use of laboratory time, to ensure that each experiment course or students have sufficient time for each experiment.

\section{B. Research on the Open Organizational Form of Experimental Content}

In the experimental content, the specialized laboratory is targeted and combined with some large experiments or teachers' projects to be opened. For example, some colleges and universities laboratory management, academic offices or departments and other departments organized the engineering practice, personalized experiments, innovative experiments, college students rese arch and innovation projects and other projects. The main sources of experimental content are the following 2 aspects:

1) In combination with the teacher's teaching and research work, the project is declared by the teacher himself.

2) The project proposed by a student according to his or her interests, such projects need to find a mentor, instructed by the instructor to declare. The experimental project shall be reported in the laboratory, and the project applicant shall be responsible for the implementation of the project and be responsible to the competent department. The use of the project funds by the project applicant shall be supervised by the competent department.

\section{Study on measures to promote laboratory opening}

To facilitate the laboratory to increase openness, so that more students and teachers to participate actively in the open laboratory activities, in addition to be recognized for the work of students and teachers, the school, the relevant authorities should also take measures. For example, the experimental course required by the laboratory must be based on the openness of the time, whether the laboratory undertakes an open laboratory project as a laboratory assessment indicator, etc. In addition, the following measures can be taken to strengthen the degree of laboratory openness:

1) Promote the advantages of the laboratory's soft and hardware environment, encourage students to enter the laboratory, and let students know the role of participating in open experimental project. This is also a certain exploration, to "virtual reality laboratory", for example, every year after the new school, laboratory instructors will produce posters, organize preaching, while holding new lectures and laboratory visits. Not only the lab leader, but also the old lab members will be involved in creating a good atmosphere for further study and research. Through these activities, students will initially understand the laboratory's experimental environment and features, and increase interest in access to the laboratory.

2) Teachers are encouraged to submit experimental items in combination with actual teaching and research work, through the project can not only exercise students, found that the potential of some students can also make a certain contribution to the teacher's research。

3) A professional laboratory opening fund is set up by the school joint social enterprise to help students participate in influential competitions in various countries, provinces, municipalities or other relevant institutions (Competition activities are organized and trained by the laboratory). 
4) Building a virtual open laboratory based on internet. Because many experimental equipment is expensive, the number of equipment can not meet the needs of the open laboratory. With the development of campus network application, it is a good choice to form a virtual laboratory based on network. This is the important application of virtual reality in teaching simulation, in fact, many domestic and foreign famous universities have built up many virtual network laboratory, students can experiment in any place, any time of the campus network.

The provincial experimental demonstration center of computer basic teaching in Taishan University has been continuously explored in accordance with the idea of open laboratory, combined with teaching and practical application, and has made certain achievements in promoting teaching with projects and competitions. In the past few years, excellent students have received dozens of projects from Tai'an science and Technology Bureau under the guidance of teachers, and received a large amount of financial support, which has injected new technological power into the local economy, in addition, students in e-commerce, threedimensional design, intelligent cars and software design and other national competitions, national awards have been achieved. Practice has proved that exploration is beneficial and opening is necessary, and this model is worth studying and popularizing.

\section{CONCLUSIONS}

Building an open laboratory is an important part of the current university laboratory reform. Defining the key contents and forms of the open laboratory and building a reasonable and effective management and incentive mechanism are very important to the sustained and effective development of the laboratory opening. Based on the analysis of the status quo of professional laboratory opening, this paper puts forward the concrete ideas of professional laboratory from open mode to management method according to the specific situation of professional experiment in colleges and universities. In conjunction with our professional laboratories, we have continued to practice the implementation of open laboratories, which have proven to be effective by practical application. Finally, some feasible ideas and methods to promote the further opening of laboratory are put forward.

\section{REFERENCES}

[1] Liao Qingmin, Qin Gangnian. Laboratory research and exploration to improve the practice ability and innovation ability of students in the [J]. Laboratory, 2010,29(4):162-165.

[2] Zheng Jiamao, et al. Constructing an open and innovative experimental teaching system to promote students' autonomous learning [J]. China's higher education, 2009(5)

[3] Wen Guanghao, Lei Cheng, Zhou Qin. Strengthen the laboratory opening and sharing to provide strong support to research and explore the [J]. Laboratory for the cultivation of innovative talents, 2009 (4).

[4] Li Yi, Li Mingdi, Jiang Aimin, et al. Innovation of open experiment teaching system [J]. laboratory research and exploration, 2012 (9): $142-143152$.

[5] Jia Fang, Ma Xiaocui, Lv Youming, et al. Break through the traditional mode and promote the laboratory reform. [J], Guangdong chemical industry, 2009, 11, (36): 204-205.

[6] Wu Yang. Research on open management mechanism of university laboratory [J]. laboratory technology and management, 2012,8 (29): 178-181. 